\title{
The Prospects of Kiswahili as a Medium of Instruction in the Tanzanian Education and Training Policy
}

\author{
Eustard Rutalemwa Tibategeza \\ University of the Free State
}

\begin{abstract}
Correspondence concerning this article should be addressed to Eustard Rutalemwa Tibategeza, Unit for Language Facilitation and Empowerment University of the Free State, P.O. BOX 339, Bloemfontein 9300, South Africa.E-mail: rutatiba@yahoo.com
\end{abstract}

Theodorus du Plessis

University of the Free State

\begin{abstract}
Correspondence concerning this article should be addressed to Theodorus du Plessis, Unit for Language Facilitation and Empowerment University of the Free State, P.O. BOX 339, Bloemfontein 9300, South Africa.E-mail: dplesslt@ufs.ac.za
\end{abstract}

\begin{abstract}
Based on the research findings, Tanzania has been cognisant of the fact that students can learn better in a language they understand. The government has been issuing policies with the intent to make Kiswahili a medium of instruction at all levels of education but without implementation. The study was conducted using documentary review, semi-structured interviews and focus group discussions to examine government generated documents, namely the Cultural Policy of 1997, Education and Training Policy of 1995 and 2014 on the use of Kiswahili as medium of instruction (MoI). The focus was to examine the government generated documents on the intent to use Kiswahili as a medium of instruction and the implementation of this decision, to analyse stakeholders' views on the appropriate medium of instruction, and to give a critical analysis as to why the proposal to make Kiswahili MoI in the Education and Training Policy could face some challenges in implementation. Previous policies, reports, the perceptions and views of education stakeholders were analysed. The findings indicate that there have been some initiatives to make Kiswahili a medium of instruction at all levels of education but such initiatives have been crippled by lack of a political will and misconceptions by some stakeholders who question the possibility for the learners to use Kiswahili as the MoI and still learn English, the language Tanzania needs for wider communication. The article concludes that although the proposed policy is suitable in Tanzania and actually long overdue, we are sceptical of its implementation. This is based on the previous state of affairs in which the government did not implement the proposed switch to Kiswahili as indicated in the reviewed policies and government pronouncements.
\end{abstract}

Keywords: medium of instruction, policy, mother tongue, language policy, language planning

Lack of proficiency in the medium of instruction (MoI) for both learners and teachers is an important factor in any education system. Qorro (2005) correctly argues, "[a]s the discussion of decision of quality education cannot be divorced from goals of education, it is equally important not to divorce the question of medium of instruction from quality education" ( $p$. 115). MoI has an important role to play in ensuring that effective learning takes place among learners. This prompts the question of whether governments in Africa, notorious for relying on the colonial language as MoI, do enough to ensure that effective learning takes place among their school learners.

The government of Tanzania had, in the past, produced rather good policies in this regard, namely the Education and Training Policy of 1995 and the Cultural Policy released in 1997. However, studies (Rubanza, 2002; Qorro, 2006; Marwa, 2014; Bikongoro, 2015) have already shown that contents of these good documents have not been implemented. Now the government has again come up with another good policy regarding the medium of instruction at all levels of education, 
the new MoI policy contained in 2014 Education and Training Policy. In terms of this policy, Kiswahili should be used as MoI at all levels of education. Given previous failures to implement the "good" policy, the main question about this revised policy is: how prepared and committed is Tanzania for its implementation? To answer this question, we shall identify the factors pertaining to the failure to implement the previous policy by analysing relevant government documents, scrutinising current evaluative studies in the field as well as recommendations made by educators and the Presidential Commission which was appointed in 1980 to review the education system in general and submit suggestions on how to improve it.

The objectives of this article, therefore, are to examine the government generated documents on the use of Kiswahili as MoI and the implementation of this decision, to analyse stakeholders' views on the appropriate MoI, and to give a critical prognosis as to why the proposed Kiswahili as MoI in the 2014 Education and Training Policy may face some challenges.

\section{Language-in-Education Policy and Medium of Instruction}

The United Nations Universal Declaration of Human Rights (1948) emphasised the right to education without any discrimination, where article 2 focuses on education without language discrimination. In the same note, a UNESCO report (1953) indicates the importance of mother tongue education by stressing "[e]ducationally he [the child] learns more quickly through it [mother tongue] than through an unfamiliar linguistic medium" (p. 11). Furthermore, UNICEF (1999) acknowledges the importance of mother tongue: "there is ample research showing that students are quicker to learn to read and acquire other academic skills when first taught in their mother tongue" (p. 41). This is because the children have internalised the language to help them to understand what they are taught.

In addition to the current international research on this topic, African scholars (Rubagumya, 2003; Wolff, 2006; Mpemba, 2007; Spolsky, 2009; Marwa, 2014; Wa-Mbaleka, 2014; Bikongoro, 2015) are also adamant about mother tongue-based education. When students have a firm grasp of what they are learning in class, MoI gives them a positive ground on which to build their understanding on the subject matter. This can only be achieved when teachers and students understand the language of education in class. According to Marwa (2014), if students are taught in a language they do not understand and if they happen to join the teaching profession, the problem will continue to the next generation. He was referring to English only policy in which poor language teaching has resulted into falling of the proficiency among the learners.

Poor mastery of the medium of instruction can have short- and long-term effects on learners. Marwa (2014) considers short-term effects as poor performance and inability to learn while in the long-term, poor mastery of MoI creates, "a systemic problem of a structural inefficiency which results into relatively less competent locally trained experts" (p. 1265). Additionally, Bikongoro (2015) accentuates, "[it] is logical to say that effective learning and assessment in a knowledge society cannot be realised unless the issue of language of instruction is resolved" (p. 7). He stresses that a learner who understands the language of education in class stands a better chance to follow what is going on in class and can acquire knowledge from different sources.

Sario et al. (2014) submit that, "[t]he use of mother tongue in the classroom makes pupils more active, participative and interactive" (p. 90). They are emphatic that this is because students in such a classroom environment have a language they can use to express their ideas, feelings and opinion. Sario et al. (2014) make an important point, noting that "since the language used in teaching at school is the same as that one used at home, parents can help their children in the teaching and learning process" (p. 90). The home language, if used in school, can encourage active participation by students in the learning process because they understand what is being discussed in class and they can answer teachers' questions as they know what they are being asked. Students use that language to construct and explain the world around them.

Bachore (2014) highlights, "Although there are many factors involved in delivering quality basic education, language is clearly the key to communication and understanding in the classroom" (p. 120). If teaching is conducted in a language students do not understand, they will be affected cognitively and more so if the teacher is also a victim of the medium of instruction. Bachore (2014) further stresses "[c]ompounded by chronic difficulties like low level of teacher education, poorly designed, inappropriate curricula and lack of adequate school facilities, submersion makes both learning and teaching extremely difficult" (p. 120). He is of the view that learning in the mother tongue has clear pedagogical advantages for children as they are likely to feel comfortable and reassured by their ability to understand and analyse information in their own language (Bachore, 2014, p. 122).

However, Bachore (2014) argues that when curriculum content is presented in an unfamiliar language "an enormous amount of time must be spent first teaching children to understand, speak, read and write L2 or a foreign language ...” (p. 123). 
He equates this with waste of valuable time that could be spent on learning academic concepts in L1. Qorro (2005) supports this idea by saying “[o]nnly the language which teachers and students understand can effectively function as the language of instruction". She emphasises that if students and teachers understand the language of the class, they will be able to discuss, debate ask and answer questions. In this way, the students will generate knowledge. On the same note, Spolsky (2009) faults the school-home language gap and says, "If the teacher and child do not understand each others" speech, teaching and learning are severely impeded" (p. 90). He is categorical that when a child's language is denied, ignored or punished by the school teacher, the child feels of disadvantaged status.

Our experience in the school setting shows that when students join the school for the first time and they are compelled to learn in a new language, frustrations are likely. However, in a study by Khan (2014), if they meet a teacher who can speak their language and makes them settle in the first days of their schooling and they continue using the home language in learning, they are likely to do better. Therefore, Khan (2014) stresses on the advantage of language in learning, arguing that, "language has a central position in all the situations involving human learning" (p. 148). The situation is worse and traumatising if students enter school not speaking the language of the class.

Moreover, Orekan (2011) accepts the fact that "one learns and continues to perform the functions of thinking, counting and even dreaming only in one's primary language" (p. 148). The mother tongue is the language through which a person knows what the world is about, particularly with regard to the learning process. That is why Khan (2014) proposes "all children, irrespective of sex, class and caste, have to move towards the school language from the home language" (p. 148). The first language is as well best suited, on pedagogical grounds, to be used as the medium of instruction.

Considering the emotional and physical needs of the child, Khan (2014) is of the concern that children need effective care during the school years. He therefore strongly suggests that during this period their mother tongue is the ideal medium of instruction because "it is as natural to them as the milk of the mother" (p. 150). He stresses that in their own native tongue children can explore their natural environment.

African scholars (Rubagumya, 2003; Wolff, 2006; Mpemba, 2007; Spolsky, 2009; Marwa, 2014; WaMbaleka, 2014; Bikongoro, 2015) seem to agree on which language is suitable for medium of instruction. They stress that the language the teachers and students understand best is the most ideal. In this case, their research suggests the mother tongue or the first language of the learners as the ideal MoI. Language- in-education policies that promote this principle are therefore inclined to produce good outcomes.

\section{English vs. Kiswahili in Tanzania}

In 1995 Kiswahili was spoken as either first language or second language by almost $95 \%$ of the population and in 2004 the National Kiswahili Council (BAKITA ${ }^{1}$ ) estimated that $99 \%$ of Tanzanians spoke Kiswahili (Batibo, 1995). Various studies (Mekacha, 1994; Rubanza, 1996) have indicated that most children acquire Kiswahili simultaneously with their respective ethnic community languages. They stress that children who join primary education conversant with one of the ethnic community languages find it easier to learn Kiswahili due to the similarities obtaining in Bantu languages, the language understood by most children. Kiswahili is a national and official language and MoI in pre-primary and primary education (URT, 1995). It is the language mostly used in all the government offices and the language of the people mostly in urban areas in their day-to-day activities.

Commenting on the English situation in Tanzania, Rubanza (2002, p. 45) asserts that students lose their English skills after completing their studies because the society they work and live in does not even use the English language. He equates English with school uniforms, in that students put it on when at school but remove it when they go back home. The same is true for English which is supposedly used at school but students switch to either Kiswahili or ethnic language when at home. In this paper Kiswahili is seen as a language understood by more than $95 \%$ of the Tanzanian population.

Apart from the enumerated advantages of the first language of the learners above, most countries in Africa, Tanzania included, still maintain the inherited colonial languages in the school setting. This is supported by the study by Wa-Mbaleka (2014) who stresses that more than half a century after UNESCO declared the importance of mother tongue education for minority children, African countries continue to use European languages. While students from minority groups try to learn and write, they do so in a language new to them. This, according to WaMbaleka (2014), "[d]oes not help them [learners] to learn effectively and efficiently". This is likely to lead such students "into more illiteracy, dropouts, poverty and undesirable life" (p. 18).

According to Marwa (2014) despite the attempt and design of the Cultural Policy in 1962 and later updated in 1997, which decided to change MoI from English to Kiswahili in all levels of education in Tanzania, the implementation has always been inactive. He is of the

\footnotetext{
BAKITA is an acronym for Baraza la Kiswahili Tanzania (National Kiswahili Council) and that is how it is popularly known in Tanzania.
} 
view that failure to implement the planned policy has always been due to mistrust among the academics, politicians, policy makers and the government in general.

English has continued to gain support among the parents and students claiming that it is the language of development, modernisation, science and technology and a language used by most people in communication across the universe. This argument gains momentum due to the support from powerful donors such as the World Bank, British Council and US-AID (Marwa, 2014). However, Bikongoro (2015) argues that "although most of the writings on the language policy in Tanzania have converged towards the justification of the uselessness of the English language in classroom instruction and assessment, such justification shed light on the tension between English and Kiswahili languages" (p. 2). To him the reality is that English has been maintained in the education setting due to global expansion of knowledge and technology advancement, of which Tanzania cannot avoid.

Although students in Tanzania, as a study by Rubagumya (2003) indicates, admit that they understand their teachers better when teaching is carried out in Kiswahili, the majority of them still think that English should be maintained as the medium of instruction in secondary schools. Explaining this controversy, Wolff (2006) asserts "decades and centuries of marginalisation have created deep-rooted negative prejudice in the minds of many Africans towards their own indigenous languages which stems from traumatic experiences during colonial times" (p. 186). Education stakeholders in Tanzania, such as parents, teachers, students and policy makers, have the impression that home languages do not enhance the performance of pupils in their examinations and their ultimate success in education. However, Rubanza (2002) points out a weakness in the language-ineducation policy that the demand for the use of Kiswahili and English at primary and secondary school levels respectively disconnect the students' experiences in Tanzania as far as MoI is concerned. He stresses that what students bring from home, whether an ethnic language or Kiswahili, is not built upon but rather wiped out and they are forced to begin afresh in a language the majority do not understand.

\section{Methods}

\section{Area of the Study and Design}

The current study was conducted in Tanzania in two regions, namely Mwanza and Dar es Salaam. The study was evaluative in nature and focused on an underdeveloped area of research in language planning, evaluating the language-in-education policy documents. In this specific case, our attention was focused on evaluating the language-in-education policy of Tanzania as contained in the 1995 and 2014 Education and Training Policy and the Cultural Policy of 1997. We also conducted interviews and focus group discussions with some education stakeholders. Based on the policy evaluation and responses from interviews and focus group discussions, a prognosis was made on the feasibility of the 2014 Education and Training Policy after it was launched on $13^{\text {th }}$ February 2015 and of its chances of success.

\section{Research Instruments}

The study applied a variety of research instruments to collect relevant data. A documentary review was undertaken on relevant policy documents to gather information on overt language policy and planning in education in Tanzania. The documents reviewed were the Education and Training Policy issued in 1995 and 2014, the Cultural Policy of 1997, the 1982 Presidential Commission report and official correspondence dossiers in eight selected schools ${ }^{2}$ in Mwanza. The documents were reviewed in order to develop the official language-in-education policy in Tanzania.

Semi-structured interviews were used with 16 teachers in the eight selected schools in the Mwanza region, with 10 parents, 8 heads of schools, 10 members of the school boards, and six officials from the Ministry of Education, Tanzania Institute of Education and HakiElimu NGO in Dar es Salaam. The authors had face to face interviews for each interviewee separately that took maximum of half an hour.

Since this study was qualitative in nature, the researchers used the quick impressionist summary and thematic analysis. In the quick impressionist summary approach the researcher summarised the key findings from documentary reviews, interviews, and focus group discussions with brief explanation, interpretation and conclusion. In the thematic analysis we subjected information obtained in the field through the research instruments to themes.

In each school 10 teachers, 16 students were randomly selected and involved in the focus group discussion. There were two groups for teachers and two groups for students in each school, each group comprising five and eight members respectively. Eight schools were randomly selected as a case study from Mwanza region in Tanzania. The aim was to solicit information on schools' language policy on the use of Kiswahili or English in carrying out day-to-day school. Students, teachers and parents were selected randomly whilst heads of schools, members of the

\footnotetext{
2 Four primary and four secondary schools which were not English medium schools
} 
school boards and other officials were purposively selected. Participants were informed of the purpose of the study and willingly accepted to give required information without demanding to be compensated.

\section{Results}

\section{Data from Documents Reviewed}

In November 1980 the government appointed the Presidential Commission chaired by Jackson Makweta to study the Tanzanian education system in general and thereafter make recommendations on how to improve it. The commission conducted an extensive study in most of the parts of Tanzania where relevant education stakeholders were interviewed. Although the language issue was not one of the terms of reference for the commission, in their report they suggested:

\section{The Ministry of Education, through its organs - the Institute of Curriculum Development, universities, and in cooperation with the National Kiswahili Council should make concrete plans to enable schools and colleges in the country to teach all subjects through the medium of Kiswahili, from Form One by January 1985 and at the university by 1992 (Ripoti - Mapendekezo ya Tume ya Rais, ${ }^{3} 1982$, p. 209).}

However, in 1983, Jackson Makweta, who was the chairperson of the commission and had then been appointed a minister of education announced that Kiswahili would not be used as MoI as anticipated. ${ }^{4}$ It was alleged that this was a result of the ruling party decision not to allow the change (Kiango, 2006).

The medium of instruction policy is dealt with in Chapter Five of the Education and Training Policy of 1995, referred to as Formal Education and Training. The policy indicates that Kiswahili shall be the medium of instruction in pre-primary and primary education while English shall be a compulsory subject in all the seven years of primary education (URT, 1995, pp. 3539). According to the document it is anticipated that pupils will have acquired and developed mastery of the English language proficiency required in post-primary levels of education, when they complete their seven years of primary education. ${ }^{5}$

The document further indicates that the opposite policy applies for secondary education. The medium

\footnotetext{
${ }^{3}$ Ripoti - Mapendekezo ya Tume ya Rais are the Kiswahili words for 'The Presidential Commission Report'

4 This was reported in Uhuru (independence), the state-owned newspaper on $08^{\text {th }}$ August 1983.

5 The primary education in Tanzania takes seven years
}

of instruction for secondary education shall be English whilst Kiswahili shall be a compulsory subject (URT, 1995, p. 45). The reason given why English should become the medium of instruction in secondary schools is that most of the instructional media and pedagogical materials are written in English, a situation that would remain the same for a long time in the foreseeable future.

Another document reviewed in connection with the language policy is the Cultural Policy released in 1997. The language issue is presented in Chapter Three of the document. Kiswahili is described as a language spoken and understood by the majority in the whole country. Therefore, it is to be proclaimed as the national language and incorporated as such in the constitution (URT, 1997, p. 16). Previously, according to this document, Kiswahili as an official language was only indicated in government pronouncements and directives which did not have legal status. Incorporating Kiswahili in the constitution would make Kiswahili formally regarded as an official language in government business, including education. Due to the fact that Kiswahili is a national language, the document makes a promise to strengthen and give adequate resources to the National Kiswahili Council and other institutions responsible for promotion of Kiswahili (URT, 1997, p. 17). Furthermore, the document states that a special programme to enable the use of Kiswahili as a medium of instruction at all levels of education would be designed and implemented (URT, 1997, p. 19). In the case of English, the document acknowledges that few people can understand, speak and write it. It is further acknowledged that continuing to use English as a sole medium of instruction of postprimary education is denying the opportunity for people to acquire knowledge (URT, 1997, p. 19). Despite this acknowledgement, English continues to be used as medium of instruction at post-primary education.

Finally, the other document reviewed is the 2014 Education and Training Policy that was launched on 13 February 2015. The language issues are discussed in Chapter Three, where different policy statements in education generally are given. The intention is for capacity building in using different languages in communication, teaching and learning. The government intends to make sure Kiswahili, English and other foreign languages are taught and mastered well at all levels of education due to their importance nationally, regionally and internationally. The document further acknowledges the current use of Kiswahili in pre-primary and primary schools, on one hand, and, on the other hand, the use of English in post primary education as contained in the 1995 Education and Training Policy.

It is echoed in the document that Kiswahili is the national language and it is used as the first or second 
language for many people in Tanzania (Jamhuri ya Muungano wa Tanzania $^{6}$ henceforth JMT, 2014, p. 36). Kiswahili is further described as the language which can be used by many people in Tanzania to get knowledge and skills in different spheres, including science and technology. As it is in the cultural policy of 1997, the government of Tanzania repeats its intent to use Kiswahili as MoI at all levels of education (JMT, 2014, p. 38). The aim is to give Tanzanians an opportunity for them to get education and training of much value nationally and internationally.

For the case of English, the document admits that English is the second or foreign language in Tanzania and therefore the government would continue to strengthen its use in teaching and learning, though not as a medium of instruction (JMT, 2014, p. 38). It is further indicated that better understanding of English and other foreign languages can enable Tanzanians to communicate with the outside world and be able to get knowledge and skills.

\section{Official Correspondences}

Official correspondences between the selected eight schools and the education authorities were also reviewed. The examined forty dossiers were from 1999 to 2008, as they were considered relevant. From studying the collected corpus of official correspondence, it was discovered that no single circular was issued detailing implementation procedures regarding 1995 and 1997 language policy for schools. For example, schools were not directed on which language to be used to document staff meeting minutes, in correspondence between the schools and the ministry, or to be used in the school motto, in the vision and mission of the schools. The documents reviewed indicate the language-in-education policy in Tanzania and the language to be used as MOI at different levels of education. They further indicate that Kiswahili and English are the languages used in education. The government's intent to make Kiswahili a medium of instruction at all levels of education is also reflected in the documents reviewed.

\section{Data from Interviews and Focus Group Discussions}

For the purpose of this article, the interviews and focus group discussions aimed at soliciting views from education stakeholders (as identified in the methodology section) on the appropriate medium of instruction in Tanzania. Their views were divided into two categories; those who were in favour of English as MoI and those who supported the use of Kiswahili as MoI.

\footnotetext{
${ }^{6}$ Jamhuri ya Muungano wa Tanzania - The United Republic of Tanzania
}

Respondents' views as captured in the interviews and focus group discussions put forward different arguments why they want English as MoI. The majority of those in favour of English said they prefer English as MOI for various reasons. Firstly, they said English is a unifying language for people from different linguistic backgrounds throughout the world. They think that students can benefit from English as they can easily communicate with other people in the world as it is a global language and they can undertake studies in the English speaking countries. Stakeholders said, "How do you expect our children to communicate with investors coming to Tanzania? They will be outweighed by people from our neighbouring countries whose command of English is better than ours".

Secondly, the majority in the interview and focus group discussion preferred English to Kiswahili because using Kiswahili only as MOI in the Tanzanian context will automatically kill English. That would result in Tanzania being isolated from the international community where English is spoken. Some stakeholders, especially heads of schools and teachers, had this to say: "If we use Kiswahili as a medium of instruction, the pressure we put on students to speak English in the schools surroundings will no longer be there. That will make most students relax in learning English and that will be the end of it [English]".

The third argument put forward especially by teachers and parents was that English should be used as MOI as there are more teaching and learning resources written in the English language. To them, switching to Kiswahili will make it difficult for students and teachers to get the required materials. When reminded that different writers would come up with different materials once Kiswahili became the official MoI, most of them said, "We buy books from developed countries where Kiswahili is not spoken. Relying on books written by Tanzanians only will deny our children to read e-books and other materials found in the Internet".

Furthermore, English was seen as a useful business language and therefore respondents think that those who master it stand a better chance to win well-paid employment opportunities. This was raised because of their experience that most foreign investors in Tanzania use English as a language of communication. Parents insisted, "When we take our children to school, we expect them to get good jobs and come back to help us. How do you expect them to get a well-paying job if they don't know the language of the employer?".

Last but not least, they argued that there is much Kiswahili at home, in the streets and most offices in Tanzania where students can easily pick up and learn Kiswahili. Most of those who supported English said, "Why should the focus be on a language our 
children know? Even some of the people who did not get secondary education can speak Kiswahili. The focus should be on learning English in schools as we cannot get it in streets". They therefore concluded that students need to seriously invest in the English language, the language not spoken by the majority in Tanzania.

Some respondents from the interviews and focus group discussion argued in favour of Kiswahili. Their first argument put forward was that Kiswahili is understood by the majority of teachers and students and therefore a language suitable in education. Officials from the ministry of education and HakiElimu said, "Over $98 \%$ of the students and teachers in schools can speak Kiswahili fluently. This will help them to interact in the classroom and be in a position to understand what is being taught. But when you insist on a language [English] both teachers and students do not understand, students will find it hard to follow in class". They stressed that some developed countries use their own languages not "imported" languages.

Secondly, they said due to a pyramid system of education in Tanzania, most of the students who cannot make it at university level do not actually need English in their day-to-day activities. They need to understand concepts in a language they know and use them for problem solving in their environment. This is because Kiswahili is used in most of the domains in Tanzania ranging from family to official issues for the majority. Some parents and members of the school boards said, "When students who do not need university education, why should they be stressed to learn a foreign language while they do not need to use it in their activities outside the school system?".

Lastly they said Kiswahili is a national language and it is steadily becoming an international language. To them, this will in the future resolve the fear people seem to have that without using English which is a language of wider communication, Tanzanians may be isolated from the international community. They referred to the recent East African Community decision to make Kiswahili one of the official languages.

Looking at the arguments in favour of English, one realises that people from different walks of life still have a misconceived idea that without using a language as MoI, students cannot acquire it.

\section{Discussion}

The main question that this article intended to answer is whether Tanzania is prepared and committed enough to make Kiswahili a medium of instruction at all levels of education as proposed in the 2014 Education and Training Policy. In this section, we discuss why this potentially good proposal may result in another implementation nightmare. From the study above with regard to the 1995 and 1997 languagein-education policy, it is noted that there are three main issues, namely whether the proposed medium of instruction can be used, whether the government is now keen enough to implement the proposed policy and whether English can be adequately mastered if taught as a subject and not used as a medium of instruction.

\section{Suitable Medium of Instruction}

The 2014 Education and Training Policy directs that Kiswahili should become a medium of instruction at all levels of education. This is a long-awaited idea since 1982 when the Presidential Commission proposed the same for improving the educational system in Tanzania. As indicated in the research by international and African scholars (UNICEF, 1999; UNESCO, 1953; Skutnabb-Kangas and Toukamaa, 1997; Rubanza, 2002; Qorro, 2005; Young, 2009; Marwa, 2014; Sario et al., 2014; Bachore, 2014; Bikongoro, 2015) children learn better in a language they understand, not a foreign language. The majority of school-age children in Tanzania go to school with a good knowledge of Kiswahili (Mekacha, 1994; Rubanza, 1996).

Education stakeholders who preferred the use of Kiswahili as MoI were of the view that Kiswahili is understood by the majority of learners, it is used in most of the domains and most children who do not make it at university level do not actually need to be stressed to learn in a language they do not understand. Rubagumya (1991) in similar vein once said, "It is believed in official circles that without English Tanzania cannot develop; and that without English as the medium of instruction the language will be lost to Tanzania irretrievably" (pp. 75-76). With this contention, parents, teachers and students have a feeling that English should remain as medium of instruction in post-primary education. However, studies in Tanzania have indicated that English is rarely used outside the classroom and most importantly students are reported to learn English only in English language classes (Rubagumya, 1991; Qorro, 2005; Mpemba, 2007).

Moreover, one of the advantages of learning through the mother tongue-based education is that learners develop a solid foundation on which all additional languages can be built if students want to learn an additional language later in the school. This is in line with the developmental interdependence hypothesis developed by Cummins (1981) where close relationship between the two languages of the child is indicated. It states: 
To the extent that instruction in Lx is effective in promoting proficiency in Lx, transfer of this proficiency to Ly will occur provided there is adequate exposure to Ly (either in school or environment) and adequate motivation to learn Ly (Cummins, 1981, p. 29).

Similarly, Young (2009) contends that "quality education occurs effectively when learners begin to read and write in their mother tongue; the language of home and community" (pp. 120-121). She further stresses that "mother tongue education has been shown to facilitate acquisition of literacy skills and provide the foundation for continuing autonomous learning" (p. 121).

Another argument put forward for not making Kiswahili a medium of instruction is that there are no teaching and learning materials in that language. However, Mwansoko (1994) argues that although Kiswahili advocates seem to be discouraged by the fact that the switch to Kiswahili medium of instruction has not been implemented, they have taken a challenge to continue with modernisation of Kiswahili to make it a viable tool of professional communication and pedagogy. Moreover, the Institute of Kiswahili Studies at the University of Dar es Salaam, the National Kiswahili Council of Tanzania and prominent individuals have ventured in publishing teaching and learning materials in Kiswahili across a good number of subjects taught from secondary to tertiary levels.

Therefore, there is a need for mass education to accept the fact that appropriate learning takes place in a language learners understand. This is in line with Burton (2013) in her study of the Philippines that indicates that "research in that country played a great role to convince policy makers on the benefits of the mother tongue instruction for language minority students" (p. 26). She highlights such benefits as "academic skills, stronger classroom participation and development of critical thinking skills" (p. 26). Otherwise, if the proposed policy does not keep in mind the views of different stakeholders, there is a danger of not getting support from the same people who are education stakeholders when it comes to implementation.

\section{Keenness of the Government to Implement the Proposed Policy}

The second issue, which is equally important, deduced from the data, particularly policies and reports reviewed, indicate that the government has been producing good policies related to the medium of instruction but these remain unimplemented. This is not the first time Tanzania is coming out with the proposal to make Kiswahili the medium of instruction at all levels of education. The first time was in 1982 through the Presidential Commission report. However, due to lack of political commitment, the proposal was never implemented.

In 1997 the government came up with the same good proposal through the Cultural Policy that a special programme to enable the use of Kiswahili as MoI would be designed and implemented (URT, 1997, p. 19). However, up until now Kiswahili is neither a medium of instruction in secondary schools nor is it in tertiary education. Kiswahili has remained MoI in pre-secondary education.

Despite the adoption of one of Africa's largest languages as a national and official language, the government has constantly insisted that English should remain the only MoI at post-primary level (URT, 1995). This decision is attributed to its tremendous power and prestige in the global market. Similarly, the decision to cling to English as a language of education at post-primary level can be attributed to what Wolff (2006) considers to be the experience the post-colonial elites have because they were successful in a foreign language-based system in which the colonial language was the dominant MoI. Students are therefore compelled to learn in English, a language neither the learners nor teachers have properly mastered. This situation has been detrimental to the learning and teaching process. The government position to cling to the use of English at post-primary level reveals a limited understanding of what an appropriate MoI in education should be.

This was also emphasised by the then president of Tanzania, Julius Nyerere, when addressing the Society for Kiswahili and Poetry:

English is the Swahili of the world and for that reason it must be taught and given the weight it deserves in our country.... It is wrong to leave English to die. To reject English is foolishness, not patriotism ... English will be the medium of instruction in secondary schools and institutions of higher education because if it is left as only a normal subject it may die. ${ }^{7}$

Nyerere seems to have had the same feeling some stakeholders have that students can only learn a new language if used as a medium of instruction. Therefore, for Tanzania to come up with the same proposal in the 2014 Education and Training Policy, leaves a lot of questions for academia and researchers.

\section{Mastering English Language}

As we have seen once Kiswahili becomes the medium

7 Nyerere's statement was reported in Mzalendo, a state-owned newspaper, October, 28, 1984 
of instruction, English will be taught as a subject in primary and secondary schools. Given the fact that the previous policy (United Republic of Tanzania, 1995) actually required English to be taught as subject from an early age and to be used as MOI, the question arises whether learners will adequately master this language within the new system. Questions were raised in our study about the level of English usage within the current system.

In the threshold level hypothesis, SkutnabbKangas and Toukamaa (1976) argue that once the children have attained threshold of competence in their first language, they can gain competence in the second language. This concurs with what Baker (2011) says on the Common Underlying Proficiency model, "irrespective of the language in which a person is operating, the thoughts that accompany talking, reading, writing and listening come from the same central engine" (p.166). This means that when a person has two or more languages, there is one integrated source of thought.

Bikongoro (2015) argues that despite the implementation of the Education and Training Policy of 1995 that directs instruction to take place in English and availability of learning materials in English for decades, "many Tanzanian students in secondary schools are challenged by a problem of English proficiency and poor performance" (p. 2). He stresses that English is responsible for students' under-achievement and it is an obstacle in accessing learning materials available in English. That being the case, students do not master the subject matter and acquisition of knowledge becomes complicated to the learners.

Marwa (2014) echoes the above argument that "the local trained graduates are competitively disadvantaged in terms of mastery and competence of the English language which is widely used as a language of wider communication" (p. 1265). He is of the view that with free movement of capital and labour across the newly formed East African Community, graduates who do not master English language will be affected in the labour market. He adds "the mere fact that a person cannot communicate effectively in English, places him in a tough spot" (p. 1265). Due to misconceived ideas held by education stakeholders including students, teachers, parents and politicians, once English is taught as a subject, learners will not be able to learn and use it for meaningful academic and pedagogical purposes (Rubanza, 2002; Qorro, 2005; Young, 2009; Marwa, 2014; Sario et al., 2014; Bachore, 2014; Bikongoro, 2015). From our study, we have seen that stakeholders have a feeling that the introduction of Kiswahili as MoI at all levels of education will result in Tanzania being cut off from the international community. They are sceptical that parents who are economically competent may resist the proposed policy and take their children to English medium schools. However, advocates of Kiswahili emphasise that English should be taught well as a subject for students to master it while keeping Kiswahili as MoI. The issue here should not be either English or Kiswahili but both languages should be seen as equally important but with different approaches.

\section{Conclusion}

The main question in this article was to see whether Tanzania is prepared and committed for the implementation of the proposed medium of instruction in the newly launched 2014 education and training policy. To answer this question, previous policies on the matter and other government pronouncements and the Presidential Commission recommendations were analysed. Furthermore, the education stakeholders' views were examined in connection with the appropriate language policy in Tanzania. Based on our findings emanating from this study, we have made a prognosis on the feasibility of the 2014 language-in-education policy.

It is proper to conclude that although the government through the 2014 Education and Training Policy has come up with a good proposal to make Kiswahili the medium of instruction, the language both learners and teachers understand well, we are sceptical as to whether Tanzania is prepared better and whether the government is more committed for implementing this policy than in the case of previous policy. As it was not possible to implement the 1982 Presidential Commission recommendation, the 1997 Cultural Policy, or respond to several researchers' constant push for the change, and since we do not see clear action plans from the government, it is not clear how serious the government is now in terms of resources and commitment to this policy change.

Moreover, findings from this study indicate that education stakeholders still think that English is a language of global business, science and technology and would therefore wish their children to be instructed in that language for them to master it. Additionally, parents still hold misconceptions held in the separate underlying proficiency theory that using both English and Kiswahili would amount to "confusion, frustration and failure" (Baker, 2011, p. 165). Due to this kind of thinking from parents and other stakeholders that children would learn a language if used as MoI, the government may lack support in implementing the proposed policy in a not so conducive environment.

The government therefore needs to carefully study the stakeholders' tension on the ground between 
what is considered a suitable medium of instruction, in this case Kiswahili and what they believe is a more useful language, in this case English. The government should communicate the implementation, provide more directives to the agents of implementation through circulars and prepare action plans for the implementation of the language-in-education policy.

\section{References}

Bachore, M. M. (2014). Learners' success in mother tongue based classroom instruction and the attitudes and perceptions of school communities. International Journal of Sociology of Education, 3(2), 118-135.

Baker, C. (2001). Foundations bilingual education and bilingualism ( $3^{\text {rd }}$ ed.). Toronto, Canada: Multilingual Matters.

Baker, C. (2011). Foundations of bilingual education and bilingualism ( $5^{\text {th }}$ ed.). Buffalo, NY: Multilingual Matters Ltd.

Batibo, H. M. (1995). The growth of Kiswahili as language of education and administration in Tanzania. In M. Putz (Ed.), Discrimination through language in Africa: Perspectives on the Namibian experience. Berlin, Germany: Mouton de Gruyter.

Bikongoro, P. F. (2015). The relevance of language policy for instruction and assessment of secondary education in Tanzania: A comparative analysis between the former Swahili and English medium students. African Educational Research Journal, 3(1), 1-8.

Burton, L. A. (2013). Mother tongue-based multilingual education in the Philippines: Studying top-down policy implementation from bottom up (Unpublished doctoral dissertation). University of Minnesota, Minneapolis, Minnesota.

Cummins, J. (1981). The role of primary language development in promoting educational success for language minority students. In California State Department of Education (Ed.), Schooling and language minority students: A theoretical framework. Los Angeles, CA: California State University.

Jamhuri ya Muungano wa Tanzania. (2014). Sera ya Elimu na Mafunzo [Education and Training Policy]. Dar es Salaam, Tanzania: Wizara ya Elimu na Mafunzo ya Ufundi.

Khan, M. T. (2014). Education in mother tongue - A child's right. International Journal of Humanities and Management Science, 2(4), 148-154.

Kiango, J. G. (2005). Tanzania's historical contribution to the recognition and promotion of Kiswahili. Africa and Asia, 5, 157-166.

Marwa, N.W.(2014). Tanzania's language of instruction policy dilemma: Is there a solution? Mediterranean Journal of Social Sciences, 5(23), 1262-1268.

Mekacha, R. D. K. (1994). Language death: Conceptions and misconceptions. Journal of Pragmatics, 21(1), 101-116.

Mpemba, T. (2007). Tanzanian policy makers' reluctance to sanction Kiswahili instructional medium in postprimary education: How do learners and instructors cope with or resist the English medium policy? (Unpublished master thesis). University of Dar es Salaam, Dar es Salaam, Tanzania.

Mwansoko, H. (1994). The post-primary swahilisation schemes in Tanzania: From debate to struggle. In C. M. Rubagumya (Ed.), Teaching and Researching Language in African Classrooms (pp. 64-78). Clevedon, UK: Multilingual Matters Ltd.

Orekan, G. (2011). Mother tongue medium as an efficient way of challenging educational disadvantages in Africa: The case of Nigeria. Scottish Languages Review, 23, 27-38.

Qorro, M. A. S. (2005). Parents' views on the medium of instruction in post-primary education in Tanzania. In B. Brock-Utne (Ed.), LOITASA research in progress (pp. 97-122). Dar es Salaam, Tanzania: KAD Associates.

Rubagumya, C. M. (1991). Language promotion for education purposes: The example of Tanzania. International Review of Education, 37(1), 67-85.

Rubagumya, C. M. (2003). English medium primary schools in Tanzania: A new 'Linguistic market' in education. In M. Qorro et al. (Eds.), Language of Instruction in Tanzania and South Africa (LOITASA) (pp. 149-169). Dar es Salaam, Tanzania: E \& D Ltd.

Rubanza, Y. I. (1996). Can a three-tier language policy work in Tanzania? A new perspective. Paper presented at the UCLA African Studies Centre, Dar es Salaam, Tanzania.

Rubanza, Y. I. (2002). Competition through English: The failure of Tanzania's language policy. In K. K. Prah (Ed.), Rehabilitating African languages. Cape Town, South Africa: The Centre for Advanced Studies of African Society.

Sario, M. L. P. et al. (2014). Behaviour manifestations of pupils using mother tongue in the classroom. Journal of Arts. Science and Commerce, 3, 90-97.

Skutnabb-Kangas, T., \& Toukamaa, P. (1997). Teaching migrant children's mother tongue and learning the language of the host country in the context of the sociocultural situation of the migrant family. Helsinki, Finland: Tampere.

Spolsky, B. (2009). Language management. Cambridge, UK: Cambridge University Press.

Tume ya Rais. (1982). Mfumo wa elimu ya Tanzania [Tanzania Education System] 1981-2000 (Vol. 1). Dar es Salaam, Tanzania: Ofisi ya Rais.

UNESCO. (1953). The use of vernacular language in 
education. Paris, France: UNESCO.

UNICEF. (1999). The state of the world's children. New York, NY: United Nations Children's Fund.

United Republic of Tanzania. (1995). Education and training policy. Dar es Salaam, Tanzania: Ministry of Education and Culture.

United Republic of Tanzania. (1997). Sera ya Utamaduni [Cultural policy]. Dar es Salaam, Tanzania: Ministry of Education and Culture.

Wa-Mbaleka, S. (2014). English teachers' perceptions of the mother tongue-based education policy in the Philippines. European Journal of Research and Reflection in Education Sciences, 2(2), 19-32.

Wolff, H. E. (2006). Background and history - language politics and planning in Africa. In UNESCO Institute for Education, Optimizing learning and education in Africa. Libreville, Gabon: Working Document.

Young, C. (2009). Good practices in mother tonguefirst multilingual education. In K. Kosonenk \& C. Young (Eds.), Mother tongue as bridge language of instruction: Policies and experiences in Southeast Asia (pp. 120-133). Bangkok, Thailand: SEAMEO. 